\title{
Six authors in search of a citation: villains or victims of the Vancouver convention?
}

\author{
Richard J Epstein
}

\begin{abstract}
Objectives-To analyse trends in the number of authors per article over the past 10 years.

Design-Analysis of articles from random volumes of eight biomedical journals.

Subjects-Cell, Nature, Proceedings of the National Academy of Sciences USA (PNAS), Journal of Clinical Investigation (JCI), Biochemical and Biophysical Research Communications (BBRC), Journal of Clinical Oncology (JCO), New England Journal of Medicine (NEJM), Lancet.

Main outcome measures-Median and modal numbers of authors.

Results-All journals except Cell and Nature showed a trend towards increasing authorship numbers over the study period. The trend was most noticeable in journals such as $J C O$ which feature clinical research. General medical journals (Lancet, NEJM) with a median of six to seven authors per article published far fewer seven author than six author studies, which suggests that author number may be influenced by the Vancouver convention which precludes citation of more than six authors.

Conclusions-The phenomenon of expanding authorship in biomedical journal articles is not explained by the hypothesis that newer research technologies have necessitated more extensive collaboration. Rather, the data suggest that conferral of authorship may sometimes have a volitional component which contributes to rising author numbers. It is proposed that replacement of the Vancouver convention with a "first author, last author" citation system may help stem this rise in author numbers.
\end{abstract}

\section{Introduction}

Success in biomedical careers has long been associated with authorship of publications in peer reviewed journals, and this association may partly explain the exponential increase in the number of articles pub-
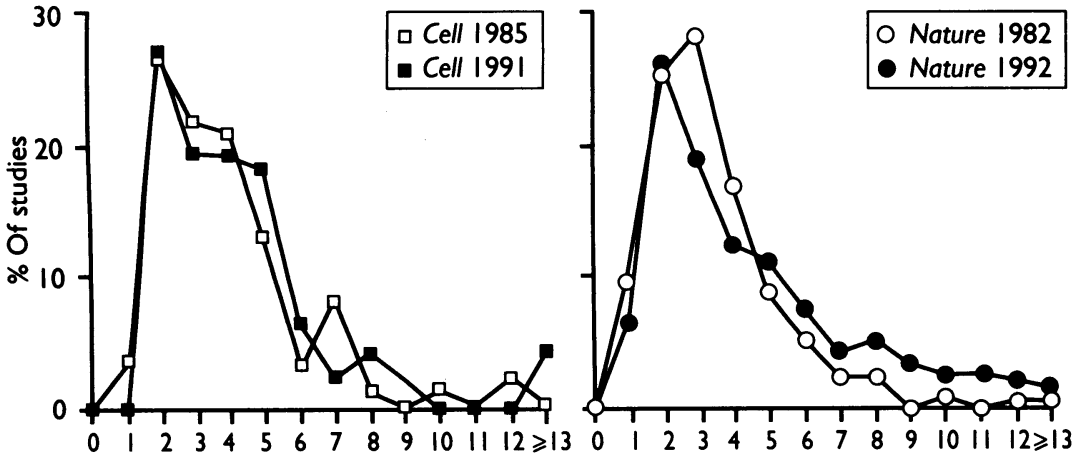

No of authors

No of authors

FIG 1-Distribution of authorship number in high profle basic research journals: "Cell" 1985-91, "Nature" 1982-92 lished over the past two decades. A parallel trend which has been widely perceived but less well documented is that of increasing numbers of authors per article. ${ }^{1-4} \mathrm{~A}$ large number of authors may be required in a study for various reasons: ( $a$ ) the need for a large team of technically specialised laboratory workers; $(b)$ the need to accrue scarce resources for study, such as clinically derived material (human tissue, blood samples) or patients with rare diseases; or $(c)$ the inherent labour intensiveness of a given project, such as cloning an unmapped gene or cooperative management of a large clinical trial. Nevertheless, it is difficult for journal editors to assess the credentials of each author of a study. ${ }^{25}$

The Vancouver convention (originated by Index Medicus and the National Library of Medicine), which states that articles contributed by more than six authors are cited in reference lists as the first six authors $e t$ al, offers an indirect method of assessing the stringency of criteria for selecting authors. This convention results in the last authors - who usually include the principal investigator-being dropped from the citation. Since principal irvestigators may be assumed to influence the selection of coauthors, the popularity of the Vancouver convention raises a testable hypothesis - namely, that senior authors may favour six author articles over seven author articles. I analysed the authorship number in eight journals over 10 years to test this hypothesis.

\section{Methods}

I selected random volumes of eight biomedical journals covering a broad spectrum of biomedical research: Cell, Nature, Proceedings of the National Academy of Sciences USA (PNAS), fournal of Clinical Investigation ( $(C I)$, Biochemical and Biophysical Research Communications (BBRC), fournal of Clinical Oncology (FCO), New England fournal of Medicine (NEFM), and the Lancet. Volumes were selected from the period 1982-92 and only original articles were eligible for analysis (including letters but not correspondence in Nature). Short reports, reviews, editorials, and hypotheses were excluded, but original articles of non-biomedical interest (such as occur in Nature and PNAS) were included. Articles citing multi-institutional groups in the title or author attribution were designated "large group collaborative studies," and such studies were grouped with multiauthor ( $>12$ authors) studies for analysis. These multiauthor and collaborative studies were accorded 13 authors in the analyses.

\section{Results}

The table summarises the data obtained from the selected journals. A total of 3366 original articles with over 18279 authors were evaluated. Figure 1 shows 
that distribution of authorship number was similar for Nature and Cell, although Cell had a higher proportion of studies with three to five authors. The number of authors per paper did not increase between 1985 and 1991 in Cell and a small increase only in the proportion of articles with 8-12 authors was seen in Nature during 1982-92. Two author studies made up the highest proportion of articles in both journals.

All journals other than Nature and Cell showed increases in median and modal author numbers over the study period. The median and modal author numbers for PNAS and $\mathcal{F C I}$ increased by $20 \%$ or more. The proportion of studies with two to three authors fell while the proportion with six to 10 rose, shifting the curve to the right. The shifting of the distribution of authorship number towards the right was more pronounced in $B B R C$ between 1982 and 1992 (fig 2). A similar trend towards increasing authorship number was seen in $\mathcal{F C O}$ (fig 2). This journal had the highest median and modal number of authors

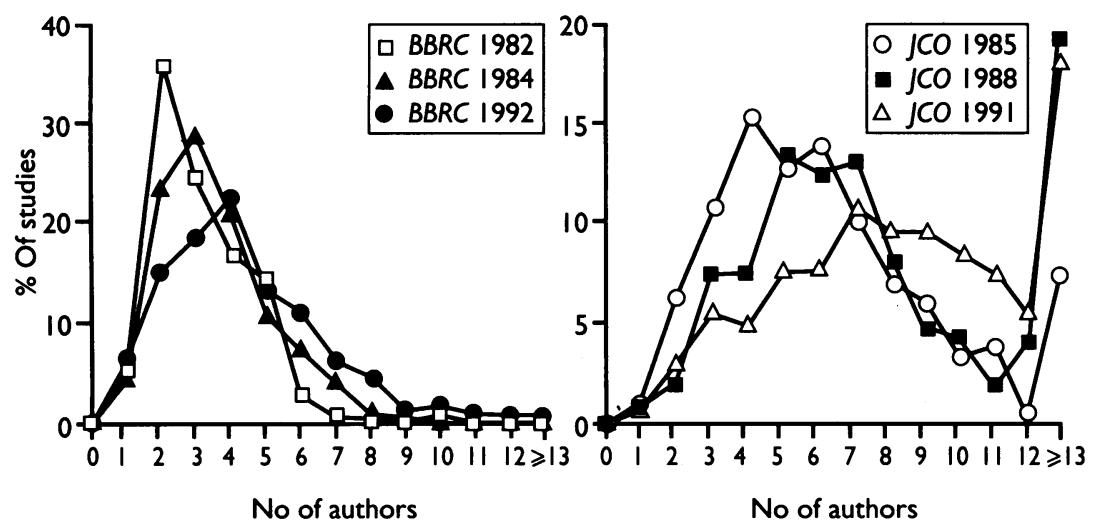

FIG 2-Distribution of authorship number over 10 years in low profile basic research journal ("Biochemical and Biophysical Research Communications") and clinical research journal ("Fournal of Clinical Oncology")

Median and modal numbers of authors for each article in journals studied

\begin{tabular}{|c|c|c|c|c|c|}
\hline $\begin{array}{l}\text { Journal (year; volume: } \\
\text { page Nos) }\end{array}$ & $\begin{array}{l}\text { Median No of } \\
\text { authors }\end{array}$ & $\begin{array}{l}\text { Modal No of } \\
\text { authors }\end{array}$ & $\begin{array}{l}\text { No of studies } \\
\text { analysed }\end{array}$ & $\begin{array}{c}\text { Total No of } \\
\text { authors }\end{array}$ & $\begin{array}{c}\% \text { Of studies with } \\
>12 \text { authors }\end{array}$ \\
\hline \multicolumn{6}{|l|}{ Cell: } \\
\hline $1985 ; 40$ & 3 & 2 & 101 & 388 & 0 \\
\hline $1991 ; 67: 1-639$ & 4 & 2 & 52 & 219 & 4 \\
\hline \multicolumn{6}{|l|}{ Nature: } \\
\hline $1982 ; 295$ & 3 & 3 & 179 & 606 & 1 \\
\hline $1992 ; 354$ & 3 & 2 & 181 & 733 & 1 \\
\hline \multicolumn{6}{|l|}{ PNAS: } \\
\hline 1982; 79: 1-208 & 3 & 2 & 42 & 150 & 0 \\
\hline 1992; 89: 4221-780 & 4 & 4 & 117 & 521 & 1 \\
\hline \multicolumn{6}{|l|}{ FCI: } \\
\hline $1982 ; 69$ & 4 & 3 & 166 & 638 & 0 \\
\hline $1991 ; 87$ & 5 & 4 & 302 & 1482 & $<1$ \\
\hline \multicolumn{6}{|l|}{$B B R C:$} \\
\hline $1982 ; 104$ & 3 & 2 & 238 & 752 & 0 \\
\hline $1984 ; 121$ & 3 & 3 & 149 & 525 & 0 \\
\hline $1992 ; 182$ & 4 & 4 & 214 & 928 & $<1$ \\
\hline \multicolumn{6}{|l|}{ FCO: } \\
\hline $1985 ; 3$ & 6 & 4 & 193 & 1220 & 8 \\
\hline $1988 ; 6$ & 7 & 6 & 159 & 1265 & 21 \\
\hline $1991 ; 9$ & 9 & 7 & 183 & 1553 & 19 \\
\hline \multicolumn{6}{|l|}{ NEJM: } \\
\hline $1985 ; 312$ & 5 & 5 & 50 & 318 & 6 \\
\hline $1986 ; 314: 1-864$ & 6 & 6 & 59 & 368 & 12 \\
\hline \multicolumn{6}{|l|}{$1987 ; 316: 825-1672$} \\
\hline $317: 1-844$ & 6 & 5 & 117 & 818 & 13 \\
\hline $1988 ; 319: 1-888$ & 6 & 6 & 59 & 403 & 12 \\
\hline \multicolumn{6}{|l|}{$1989 ; 320: 1-880$} \\
\hline $321: 1-916$ & 7 & 6 & 117 & 882 & 17 \\
\hline $1990 ; 323$ & 7 & 6 & 61 & 435 & 18 \\
\hline $1991 ; 324,325$ & 6 & 4 & 116 & 873 & 22 \\
\hline \multicolumn{6}{|l|}{ Lancet } \\
\hline $1985 ; \mathrm{i}$ & 5 & 3 & 64 & 348 & 6 \\
\hline 1986 ; i, ii & 5 & 3,6 & 125 & 752 & 8 \\
\hline $1989 ; \mathrm{i}$ & 6 & 6 & 104 & 662 & 11 \\
\hline $1990 ; 336$ & 6 & 5 & 126 & 805 & 9 \\
\hline $1991 ; 337,338$ & 6 & 6 & 92 & 595 & 11 \\
\hline Total & & & 3366 & 18279 & \\
\hline
\end{tabular}

*Studies with $>12$ authors analysed as if having 13 authors.

PNAS=Proceedings of the National Academy of Science USA, $\mathscr{C} I=$ fournal of Clinical Investigation, $B B R C=$ Biochemical and Biophysical Research Communications, $\mathcal{F C O}=$ foumal of Clinical Oncology, NE $f M=$ New England foumal of Medicine. and published a high proportion of multiauthor or collaborative studies $(21 \%$ in 1988$)$.

This increased number of multiauthor studies is not confined to journals publishing clinical trials. The $N E \mathcal{H}$, a general medical journal that publishes both clinical research and medically relevant basic research, also had a threefold to fourfold increase in the proportion of multiauthor or collaborative articles between 1985 and 1991 (table). These studies accounted for $22 \%$ of published original articles by 1991. This increase in large group studies is associated with about a $50 \%$ fall in articles by one to three authors (data not shown). As with most of the other journals surveyed, NEFM had a general increase in authorship number as shown by the increase in mode from 5 to $6(20 \%)$ and in median from 5 to 7 (40\%) between 1985 and 1990 (table). The distribution of authorship number showed a sigmoidal increase up to six authors followed by a steep fall to seven authors and more gentle fall to 11 authors (fig 3 ). Similar trends were seen in the Lancet, another general medical journal. The Lancet had a steeper fall from six to seven authors, perhaps because they published a smaller proportion of large group studies (and hence had a higher modal ' 6 ' value) than NEFM.

Figure 4 shows how the rapid fall from six to seven authors is influenced by alterations in the overall distribution of authorship numbers. Only a 3\% absolute fall in the number of papers with seven authors was seen in the NEFM during 1985-9, when the modal author number was 5 . A $10 \%$ fall in seven author papers occurred during 1989-91 when the modal author number rose to 6 . This amounts to a relative frequency decline of over $50 \%$. Similarly, for the Lancet in 1985-9 the modal author number was 5 and there was an absolute fall in seven author papers of $6 \%$, whereas in 1989-91 the mode was six authors and the fall in seven author papers was papers was $10 \%$. Again, this absolute reduction represents a relative fall of seven author articles of more than $50 \%$ when compared with the frequency of six author articles (fig 4).

\section{Discussion}

Three patterns of distributions of authorship number are suggested by these data: $(a)$ the "left shifted" pattern seen in high profile basic research journals (Nature, Cell), in which over $90 \%$ of articles have one to five authors (mode 2); (b) the "right shifted" pattern characterised by few small group studies and many large group studies (mode 7) seen in low profile basic research $(B B R C)$ and clinical research $(F C O)$ journals; and $(c)$ a rapid fall from six to seven authors (mode 6) in general medical journals (NEFM, Lancet). A threefold increase in the proportion of large group ( $>12$ authors or multi-institutional) studies and a reduced proportion of small group (1-3 author) studies was seen in both general and specialist clinical journals.

Increased complexity of analytical methodology seems an unlikely explanation for this trend. An alternative hypothesis is that clinical studies have evolved towards a larger format over the past decade, with a corresponding increase in the number of contributors. A further possibility is that either the prestige or the style of the journals has altered over the study period, thus encouraging submission (or acceptance) of larger studies.

The rapid fall from six to seven authors seen in both general medical journals suggests a preference by some principal authors for six rather than seven authors. This raises the possibility that in some instances the number of authors may be negotiable: by limiting the number of cited authors to six, last authors receive acknowledgment in citation listings. If this theory were 


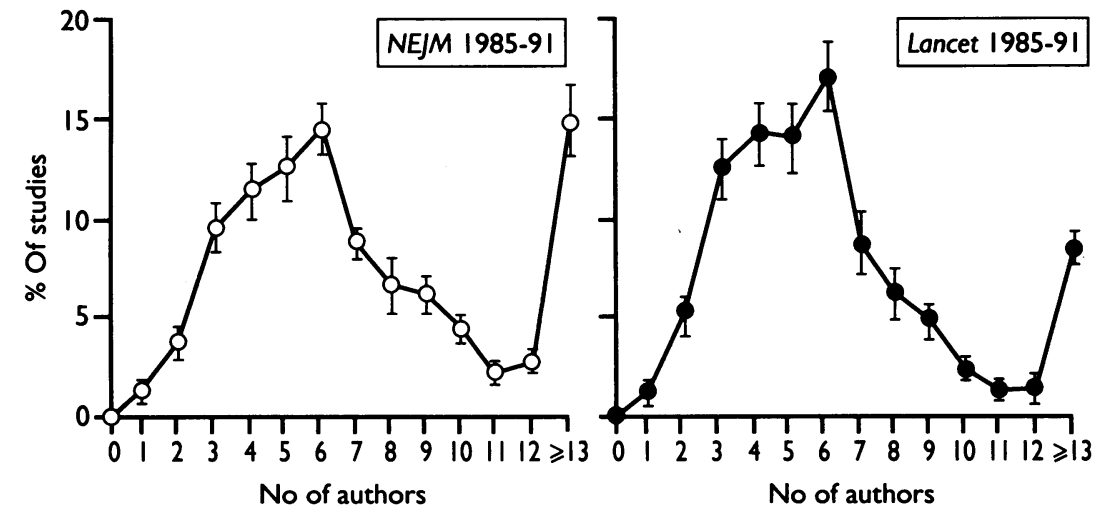

FIG 3-Distribution of authorship number in general medical journals during 1985-91. Standard error bars are based on 10 measurements for "New England fournal of Medicine" and on nine for "Lancet"
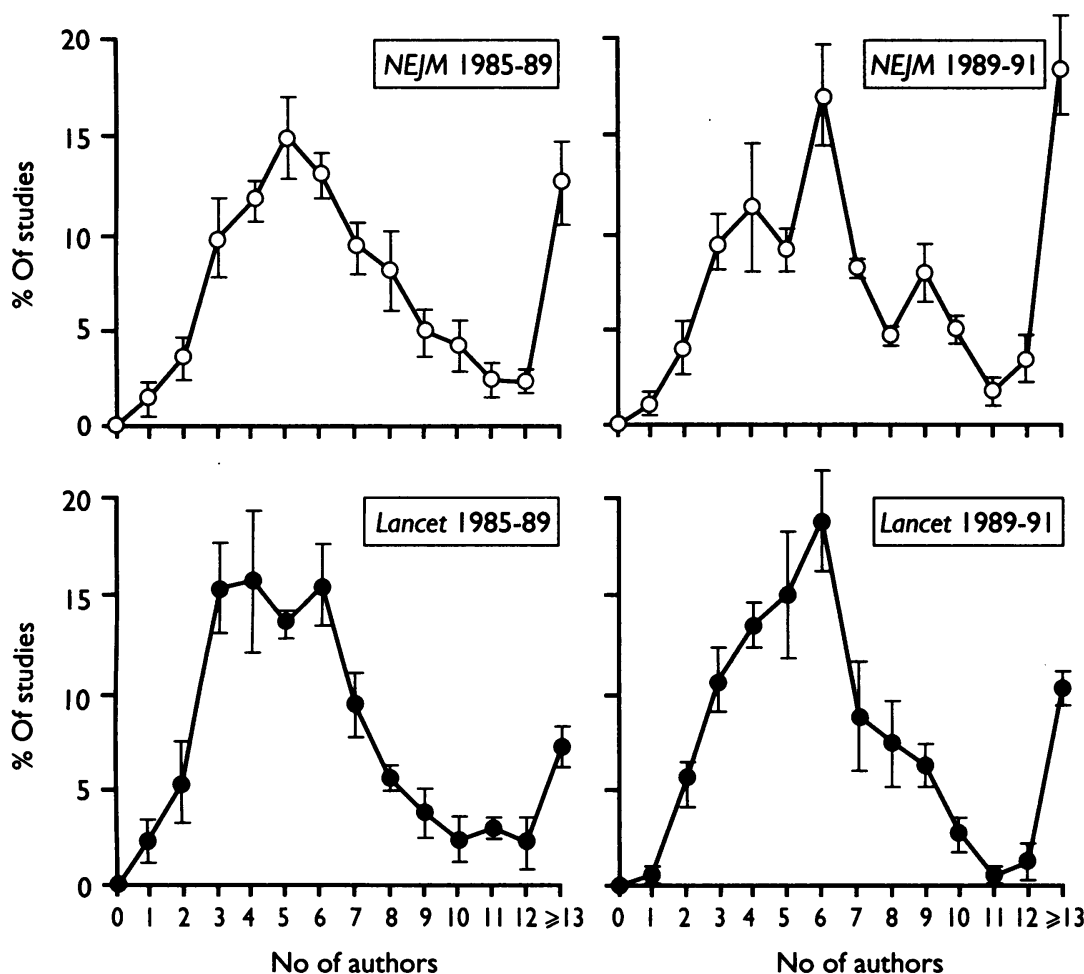

FIG 4-Effect of shifts with time in distribution of median and mode authorship number on rapid fall from six to seven authors in two genral medical journals

true a similar pattern might be expected in other journals. The different modal authorship numbers could explain why this was not seen. $\mathscr{F C O}$ in 1991 is unlikely to exhibit a rapid fall from six to seven authors-for example, because the distribution is already shifted far to the right; conversely, basic research journals such as Nature and PNAS cannot exhibit the pattern until their modal author number increases to 6 . Moreover, the ongoing trend towards increasing author numbers in journals such as NEFM (in which median authorship had already reached 7 by 1989) indicates that the pattern may disappear again.

To determine whether this "Vancouver effect" is real, a more exhaustive analysis is needed of all volumes of a wider spectrum of journals. Despite its limitations, however, this study helps clarify some aspects of the phenomenon of expanding biomedical authorship. Firstly, the hypothesis that increasing author numbers reflect the development of more labour intensive research technologies becomes untenable given the continuing high quality small group productivity seen in Nature and Cell. Secondly, the apparent occurrence of a rapid fall from six to seven authors seen in some journals suggests that conferral of authorship may sometimes have a volitional component. This phenomenon may either favour or oppose the career interests of potential coauthors. In the case of an article written by five authors, for example, the availability of one extra slot may work to the advantage of a colleague whose goodwill is valued but whose involvement with the project had been only marginal; such circumstances may help create a dip in the number of articles with five authors (figs 2 and 4 ) which further accentuates the peak at six authors. For papers with seven potential authors the principal investigator may decide to omit one author and instead acknowledge his or her help at the end of the article. The excluded authors "lose a publication," which may adversely affect their academic career. Longer term consequences of this trend could include an increased counterproductive emphasis on first author publication.

The uncontrolled increase in the number of authors might be remediable to some extent by journals devising a collective policy. One such strategy would be to cite references by first and last author et int (and intervening). This would reduce the number of authors listed while still providing unambiguous access to the publication, acknowledgment of the primary researcher, and identification of the department or laboratory (usually that of the last author). This should not reduce the usefulness of the reference, since the prime function of a citation is that of referring an interested reader to another work rather than that of publicly applauding the contribution of individual authors. Paradoxically, then, reduced citation visibility for coauthors could result in middle authorship continuing to be regarded as an earned (and hence valued) privilege rather than as a right, a favour, a payback, or an inconsequential bagetelle.

\section{RJE is supported by the National Institutes of Health.}

1 Hamilton DP. Publishing by-and for - the numbers. Science $1990 ; 250$ 1331-2.

2 Burman KD. "Hanging from the masthead": reflections on authorship. Ann Intern Med 1982;97:602-5.

3 Alvarez-Dardet C, Gascon E, Mur P, Nolasco A. 10-year trends in the journal's publications. N Engl f Med 1985;312:1521-2.

4 Sobal J, Ferentz KS. Abstract creep and author inflation. $N$ Engl $\mathcal{F ~ M e d}$ 1990;323:488-9.

5 Editorial Policy Committee, Council of Biology Editors. Ethics and policy in scientific publication. Bethesda, MD: Council of Biology Editors, 1990: 175-201.

(Accepted 22 December 1992)

\section{Apology}

\section{Ethical issues in randomised prevention trials}

We apologise to Professor Nicholas Wald and to readers who were offended by the picture that appeared with Professor Wald's article on ethical issues in randomised prevention trials (27 February, p 563). The picture, which was not selected by Professor Wald and was not seen by him until after publication, showed a man having his nose measured by Nazis for infamous racial purposes. The picture was selected by the editorial team from a picture library to illustrate the ethical difficulties that may arise from research. The selection of this picture to illustrate Professor Wald's article was a poor decision. 